\title{
Non-Vitamin K Antagonist Oral Anticoagulants Versus Warfarin in Patients with Atrial Fibrillation with Coronary or Peripheral Artery Disease A Meta-Analysis
}

\author{
Hao Zhang, ${ }^{1 *}$ MS, Zhengbiao Xue,${ }^{2 *}$ MS, Dongqian Yi, ${ }^{3}$ MS, Xiaobo Li, ${ }^{1}$ MS, \\ Yanwu Tan, ${ }^{1}$ MD and Jianwen $\mathrm{Li},{ }^{1}$ MD
}

\begin{abstract}
Summary
The efficacy and safety of non-vitamin K antagonist oral anticoagulants (NOACs) in atrial fibrillation (AF) with coronary or peripheral artery disease (CAD or PAD) remain largely unresolved. We, therefore, conducted a meta-analysis to explore the effect of NOACs compared with warfarin in these populations.

We systematically searched the Cochrane Library, PubMed, and Embase databases for randomized controlled trials (RCTs) involving NOACs versus warfarin in AF patients with CAD or PAD. A random-effect model was selected to pool the risk ratios (RRs) and 95\% confidence intervals (CIs).

A total of 7 RCTs were included. In AF patients with CAD, compared with warfarin use, the use of NOACs was associated with reduced risks of stroke/systemic embolism (RR 0.82; 95\% CI 0.70-0.96) and intracranial hemorrhage (RR 0.41; 95\% CI 0.26-0.63), but NOACs versus warfarin showed similar risks of allcause death (RR 0.95; 95\% CI 0.86-1.05), cardiovascular death (RR 0.95; 95\% CI 0.80-1.13), stroke (RR 0.80; 95\% CI 0.64-1.00), myocardial infarction (RR 1.00; 95\% CI 0.83-1.21), and major bleeding (RR 0.82; 95\% CI 0.65-1.04). Among patients with $\mathrm{AF}$ and PAD, NOACs versus warfarin had similar risks for stroke (RR 0.93; 95\% CI 0.61-1.42), myocardial infarction (RR 1.10; 95\% CI 0.64-1.90), all-cause death (RR 0.91; 95\% CI 0.70-1.19), major bleeding (RR 1.12; 95\% CI 0.70-1.81), and intracranial hemorrhage (RR 0.54; 95\% CI 0.161.85).
\end{abstract}

NOACs seem to be at least as effective and safe as warfarin in AF patients with CAD. whereas NOACs versus warfarin have similar efficacy and safety in patients with PAD.

(Int Heart J 2020; 61: 231-238)

Key words: Anticoagulation therapy, Non-valvular atrial fibrillation, Stroke, Coronary heart disease, Arteriopathy

A trial fibrillation (AF) is associated with increased risks of thromboembolic events, and oral anticoagulation therapy is a central aspect of AF management. ${ }^{1-4)}$ Vitamin $\mathrm{K}$ antagonists (VKAs), such as warfarin, have been demonstrated to be effective for stroke prevention in AF patients; however, VKAs have several limitations (e.g., multiple interactions with other drugs or foods, narrow therapeutic window, the need for international normalized ratio monitoring). More recently, the non-vitamin $\mathrm{K}$ antagonist oral anticoagulants (NOACs), such as dabigatran, rivaroxaban, apixaban, and edoxaban, have changed the landscape of stroke prevention, ${ }^{5}$ given that these drugs are at least as effective as VKAs and even have a better safety profile in 4 phase III randomized clinical trials (RCTs). ${ }^{6-9}$

Coronary or peripheral artery disease (CAD or PAD) often accompanies AF with incidences up to $\left.20 \%-40 \% .^{10}\right)$ Management of patients with both AF and CAD or PAD includes anticoagulation therapy and antiplatelet therapy. ${ }^{11,12)}$ However, the combined co-administration of warfarin and antiplatelet therapy does not reduce the risks of recurrent coronary events and thromboembolism but increases the bleeding risk. ${ }^{13)}$ Studies have focused on the role of NOACs in patients with concomitant AF and CAD or PAD. Till now, several sub-analyses of NOAC trials (RE-LY, ROCKET-AF, ENGAGE AF-TIMI 48, and ARIS-

From the ${ }^{1}$ Department of Cardiovascular Medicine, Xiangdong Hospital Hunan normal University, Liling, China, ${ }^{2}$ Department of Critical Care Medicine, First Affiliated Hospital of Gannan Medical University, Ganzhou, China and ${ }^{3}$ Department of Gastroenterology, Xiangdong Hospital Hunan normal University, Liling, China.

*These authors contributed equally to this work.

This study was supported by Dr. Jianwen Li (B2017074).

Address for correspondence: Jianwen Li, MD, Department of Cardiovascular Medicine, Xiangdong Hospital Hunan normal University, Liling, 412200, Hunan 412200 China. E-mail: 2898231399@qq.com

Received for publication April 21, 2019. Revised and accepted July 5, 2019

Released in advance online on J-STAGE March 14, 2020.

doi: 10.1536/ihj.19-202

All rights reserved by the International Heart Journal Association. 
TOTLE) have compared the efficacy and safety outcomes of NOACs versus warfarin for stroke prevention in AF patients with $\mathrm{CAD}^{14-17)}$ or PAD. ${ }^{18-20)}$ Therefore, based on the data from these RCTs, we conducted a meta-analysis to explore the efficacy and safety of NOACs compared with warfarin in these populations.

\section{Methods}

In this meta-analysis, the presentations were based on the Preferred Reporting Items for Reporting Systematic Reviews and Meta-analyses (PRISMA) of studies that evaluate healthcare interventions. ${ }^{21}$ )

Literature search: We systematically searched the Cochrane Library, PubMed, and Embase databases for relevant studies reporting the use of NOACs in patients with concomitant $\mathrm{AF}$ and $\mathrm{CAD}$ or PAD that were published before March 2019. No language restrictions were imposed during the searches. To identify studies involving relevant participants, we performed the search with keywords including the following terms: AF, peripheral artery disease, coronary disease, coronary heart disease, ischemic heart disease, CAD, myocardial ischemia, angina pectoris, and coronary stenting. To identify studies involving antithrombotic therapies, we performed the search with keywords including the following terms: non-vitamin $\mathrm{K}$ antagonist oral anticoagulants, direct oral anticoagulants, dabigatran, rivaroxaban, apixaban, edoxaban, darexaban, betrixaban, ximelagatran, otamixaban, and argatroban. To identify studies involving relevant outcomes, we used the following keywords: death, cardiovascular death, myocardial infarction, stent thrombosis, stroke, systemic embolism, major bleeding, and intracranial hemorrhage. These 3 categories of keywords were combined using the Boolean operator "and." We also reviewed reference lists to identify relevant studies. In addition, we searched ClinicalTrials. gov (https://www.clinicaltrials.gov/) to obtain information on studies that were terminated without publication.

Inclusion and exclusion criteria: Studies satisfying the following criteria were included: (1) participants of the study: AF patients with CAD or PAD; (2) design of the study: RCTs, sub-analyses of RCTs; and (3) comparisons of the study: the efficacy and safety outcomes of NOACs versus warfarin. Studies that not using warfarin as a reference were excluded in this meta-analysis. Duplicated studies or certain publication study types with no data were also excluded. Studies enrolling patients undergoing percutaneous coronary intervention (PCI) or acute coronary syndrome were also excluded.

Efficacy and safety outcomes: The efficacy outcomes included stroke and systemic embolism (SEE), all-cause death, cardiovascular death, and myocardial infarction (MI). The safety outcomes included major bleeding and intracranial hemorrhage. Bleeding was defined according to the International Society on Thrombosis and Haemostasis. ${ }^{22)}$

Data extraction: All the studies retrieved by the search strategy were independently screened by 2 reviewers $(\mathrm{Z}-\mathrm{H}$ and $\mathrm{X}-\mathrm{ZB}$ ). The first phase of screening was performed by reading titles and/or abstracts, and the second phase of screening was to review the full text. Ultimately, articles meeting the eligibility criteria were included. Disagreements were settled by discussion with a third author (LJW).

For each study, the extracted information included the following characteristics: name of the first author, year of publication, study design, inclusion criteria, age, proportion of female patients, total number of patients, duration of follow-up, dose of anticoagulants used, and endpoints and their definitions.

Quality assessment: The methodological quality of the included studies was evaluated for the risk of bias using the Cochrane risk of bias assessment tool independently by 3 reviewers (Z-H, X-ZB, and L-JW). ${ }^{23)}$ Three reviewers scored the potential for bias risk of each study as "low," "unclear," or "high" risk in 7 domains: random sequence generation (selection bias), allocation concealment (selection bias), blinding of participants and personnel (performance bias), blinding of outcome assessment (detection bias), incomplete outcome data (attrition bias), selective reporting (reporting bias), and other bias. If 3 out of 7 items were "low," this study was defined as "low risk."

Statistical analysis: Statistical analysis was performed using Review Manager Version 5.3 (Cochrane Collaboration, Copenhagen, Denmark). For each study, the included data were the risk ratio (RRs) and the corresponding 95\% confidence intervals (CIs). The natural logarithm of the RR $(\log [R R])$ and its standard error (SElog $[R R])$ were calculated and then pooled using statistical software. In view of the different drugs and doses across the included studies, we selected a random-effect model to evaluate the treatment outcomes, which accounts for variability both within studies and between studies. ${ }^{24}$ The heterogeneity across the included studies was measured with an $\mathrm{I}^{2}$ statistical test, with values of $25 \%, 50 \%$, and $75 \%$ representing low, moderate, and high heterogeneity, respectively. The statistical significance threshold was set at $P<0.05$.

\section{Results}

Search selection: The search steps are illustrated in Figure 1. A total of 648 potential articles (475 through PubMed, 132 through Embase, and 41 through the Cochrane Library) were identified through the electronic retrieval strategies, and no additional studies were identified through manual searches. After duplicates were removed, 613 records remained. Based on the title- and/or abstractscreenings, 598 records were excluded, and 15 articles remained for the full-text review. Eight articles were subsequently excluded because 1 study $^{25}$ did not compare the outcomes of NOACs with warfarin, 1 study $^{26)}$ included AF patients without CAD, 2 studies $^{27,28)}$ did not report the outcomes of interest, 1 study $^{29)}$ was an observational study, 2 studies $^{30,31)}$ included AF patients undergoing PCI, and 1 article $^{32)}$ was excluded for duplicate data. Finally, 7 RCTs (4 studies for $\mathrm{AF}$ and $\mathrm{CAD}$, and 3 studies for $\mathrm{AF}$ and PAD) ${ }^{14-20)}$ were included in this meta-analysis.

Baseline characteristics of the included studies are shown in the Table. There were 4 studies $^{14-17)}$ that enrolled 19267 AF patients with CAD, and 3 studies ${ }^{18-20)}$ included 2564 AF patients with PAD. The risk of bias of the included studies was assessed and is summarized in Figure 


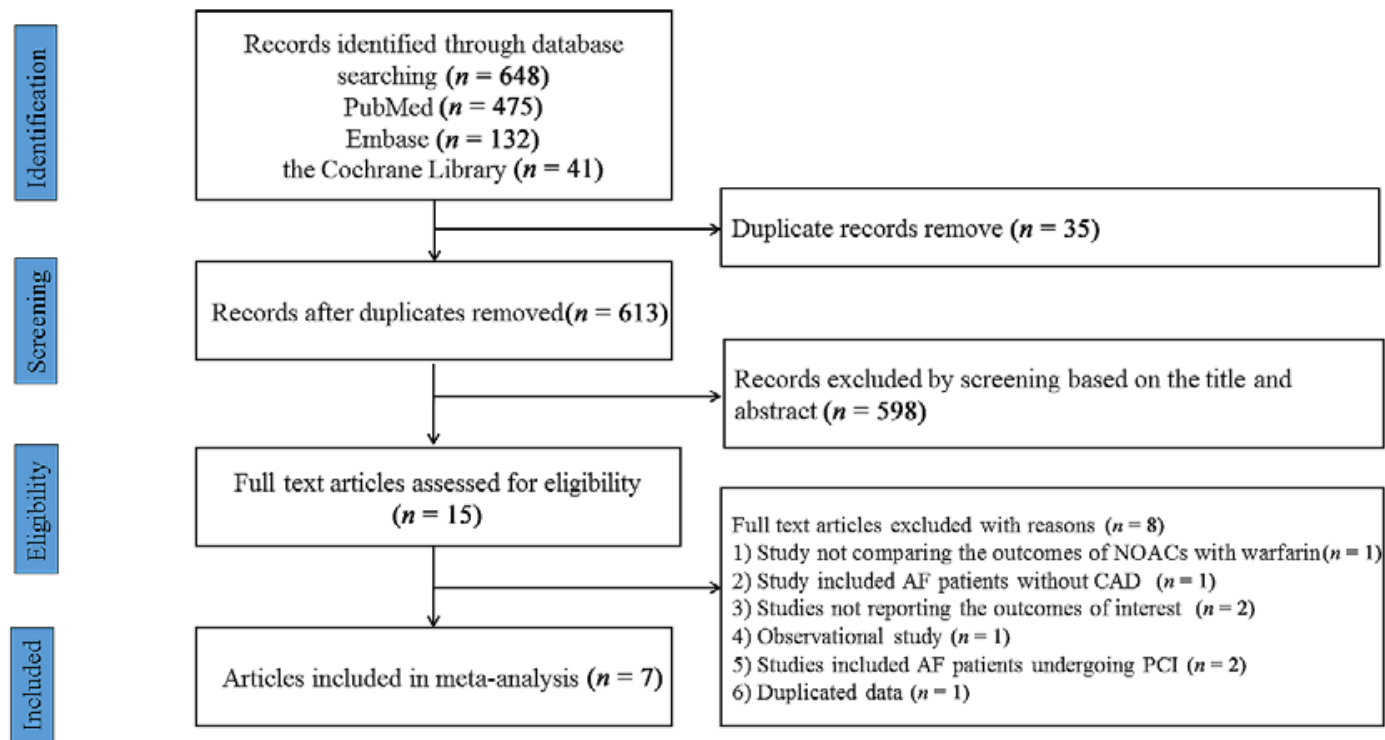

Figure 1. PRISMA diagram of the study selection process for the meta-analysis. AF indicates atrial fibrillation; NOACs, non-vitamin $\mathrm{K}$ antagonist oral anticoagulants; PCI, percutaneous coronary intervention; and CAD, coronary artery disease.

Table. Clinical Characteristics of the Included Randomized Controlled Trials

\begin{tabular}{|c|c|c|c|c|c|c|c|c|}
\hline Study, year & Study participants & Group & Number & $\begin{array}{l}\text { Age } \\
\text { (years) }\end{array}$ & $\begin{array}{c}\text { Female } \\
(\%)\end{array}$ & $\begin{array}{l}\text { Aspirin } \\
(\%)\end{array}$ & $\begin{array}{l}\mathrm{P}_{12} \mathrm{Y}_{12} \\
\text { inhibitor } \\
(\%)\end{array}$ & $\begin{array}{l}\text { Follow-up } \\
\text { (months) }\end{array}$ \\
\hline $\begin{array}{l}\text { Hohnloser, } \\
2012\end{array}$ & $\mathrm{AF}$ patients with prior $\mathrm{CAD} / \mathrm{MI}$ & $\begin{array}{l}\text { Dabigatran } 110 \mathrm{mg} \\
\text { Dabigatran } 150 \mathrm{mg} \\
\text { Warfarin }\end{array}$ & $\begin{array}{l}1886 \\
1915 \\
1849\end{array}$ & NA & NA & NA & NA & 24 \\
\hline Bahit, 2013 & $\mathrm{AF}$ patients with prior $\mathrm{CAD}$ & $\begin{array}{l}\text { Apixaban } 5 \mathrm{mg} \\
\text { Warfarin }\end{array}$ & 6639 & 70 & 29.8 & $42.2 \%$ & $3.4 \%$ & $\begin{array}{l}14.4 \\
13.1\end{array}$ \\
\hline $\begin{array}{l}\text { Mahaffey, } \\
2014\end{array}$ & AF patients with prior MI & $\begin{array}{l}\text { Rivaroxaban } 20 \mathrm{mg} \\
\text { Warfarin }\end{array}$ & $\begin{array}{l}1182 \\
1286\end{array}$ & $\begin{array}{l}73 \\
74\end{array}$ & $\begin{array}{l}24.5 \\
26.3\end{array}$ & $\begin{array}{l}48.1 \\
46.8\end{array}$ & $\begin{array}{l}2.7 \\
4.0\end{array}$ & 23.6 \\
\hline $\begin{array}{l}\text { Zelniker, } \\
2019\end{array}$ & $\mathrm{AF}$ patients with prior $\mathrm{CAD}$ & $\begin{array}{l}\text { Edoxaban } 60 \mathrm{mg} \\
\text { Edoxaban } 30 \mathrm{mg} \\
\text { Warfarin }\end{array}$ & $\begin{array}{l}1478 \\
1530 \\
1502\end{array}$ & $\begin{array}{l}72.1 \\
72.1 \\
72.3\end{array}$ & $\begin{array}{l}23.1 \% \\
23.5 \% \\
23.2 \%\end{array}$ & $\begin{array}{l}45.7 \% \\
43.9 \% \\
45.9 \%\end{array}$ & NA & 34.1 \\
\hline Jones, 2014 & AF patients with $\mathrm{PAD}$ & $\begin{array}{l}\text { Rivaroxaban } 20 \mathrm{mg} \\
\text { Warfarin }\end{array}$ & $\begin{array}{l}401 \\
438\end{array}$ & 74 & $27.7 \%$ & $\begin{array}{l}39.7 \% \\
39.0 \%\end{array}$ & $\begin{array}{l}2.2 \% \\
2.7 \%\end{array}$ & 18.8 \\
\hline $\begin{array}{l}\text { Cunningham, } \\
2016\end{array}$ & AF patients with PAD & $\begin{array}{l}\text { Edoxaban } 60 \mathrm{mg} \\
\text { Edoxaban } 30 \mathrm{mg} \\
\text { Warfarin }\end{array}$ & 841 & NA & NA & NA & NA & 33.6 \\
\hline $\mathrm{Hu}, 2017$ & $\mathrm{AF}$ patients with $\mathrm{PAD}$ & $\begin{array}{l}\text { Apixaban } 5 \mathrm{mg} \\
\text { Warfarin }\end{array}$ & $\begin{array}{l}442 \\
442\end{array}$ & 73 & $28.4 \%$ & $\begin{array}{l}36.2 \% \\
41.9 \%\end{array}$ & $\begin{array}{l}4.8 \% \\
2.7 \%\end{array}$ & 21.6 \\
\hline
\end{tabular}

AF indicates atrial fibrillation; $\mathrm{CAD}$, coronary artery disease; MI, myocardial infarction; NA, not available; PAD, peripheral artery disease; and RCTs, randomized controlled trials.

2. Generally, a low risk of bias was identified across the 7 included studies.

Efficacy and safety of NOACs versus warfarin in AF patients with CAD:

Efficacy of NOACs versus warfarin As presented in Figure 3, when compared with warfarin, the use of NOACs was associated with reduced risk of stroke/SSE (RR 0.82; 95\% CI $0.70-0.96 ; P=0.02 ; I^{2}=26 \%$ ), but NOACs versus warfarin showed similar risks of all-cause death (RR 0.95; 95\% CI 0.86-1.05; $\left.P=0.30 ; \mathrm{I}^{2}=3 \%\right)$, cardiovascular death (RR $0.95 ; 95 \%$ CI $0.80-1.13 ; P=0.57 ; I^{2}=32 \%$ ), stroke (RR 0.80; 95\% CI 0.64-1.00; $P=0.05 ; \mathrm{I}^{2}=9 \%$ ), and MI (RR 1.00; 95\% CI 0.83-1.21; $P=0.98 ; \mathrm{I}^{2}=$
$35 \%)$.

Safety of NOACs versus warfarin As shown in Figure 3, when compared with warfarin, the use of NOACs was associated with decreased risk of intracranial hemorrhage (RR $0.41 ; 95 \%$ CI $0.26-0.63 ; P<0.0001 ; I^{2}=0 \%$ ), but NOACs versus warfarin had a similar risk of major bleeding (RR 0.82; 95\% CI 0.65-1.04; $P=0.10 ; \mathrm{I}^{2}=81 \%$ ).

Efficacy and safety of NOACs versus warfarin in AF patients with PAD:

Efficacy of NOACs versus warfarin As shown in Figure 4, among patients with AF and PAD, NOACs versus warfarin had similar risks for all-cause death (RR $0.91 ; 95 \%$ CI $\left.0.70-1.19 ; P=0.50 ; \mathrm{I}^{2}=0 \%\right)$, MI (RR $1.10 ; 95 \%$ CI 


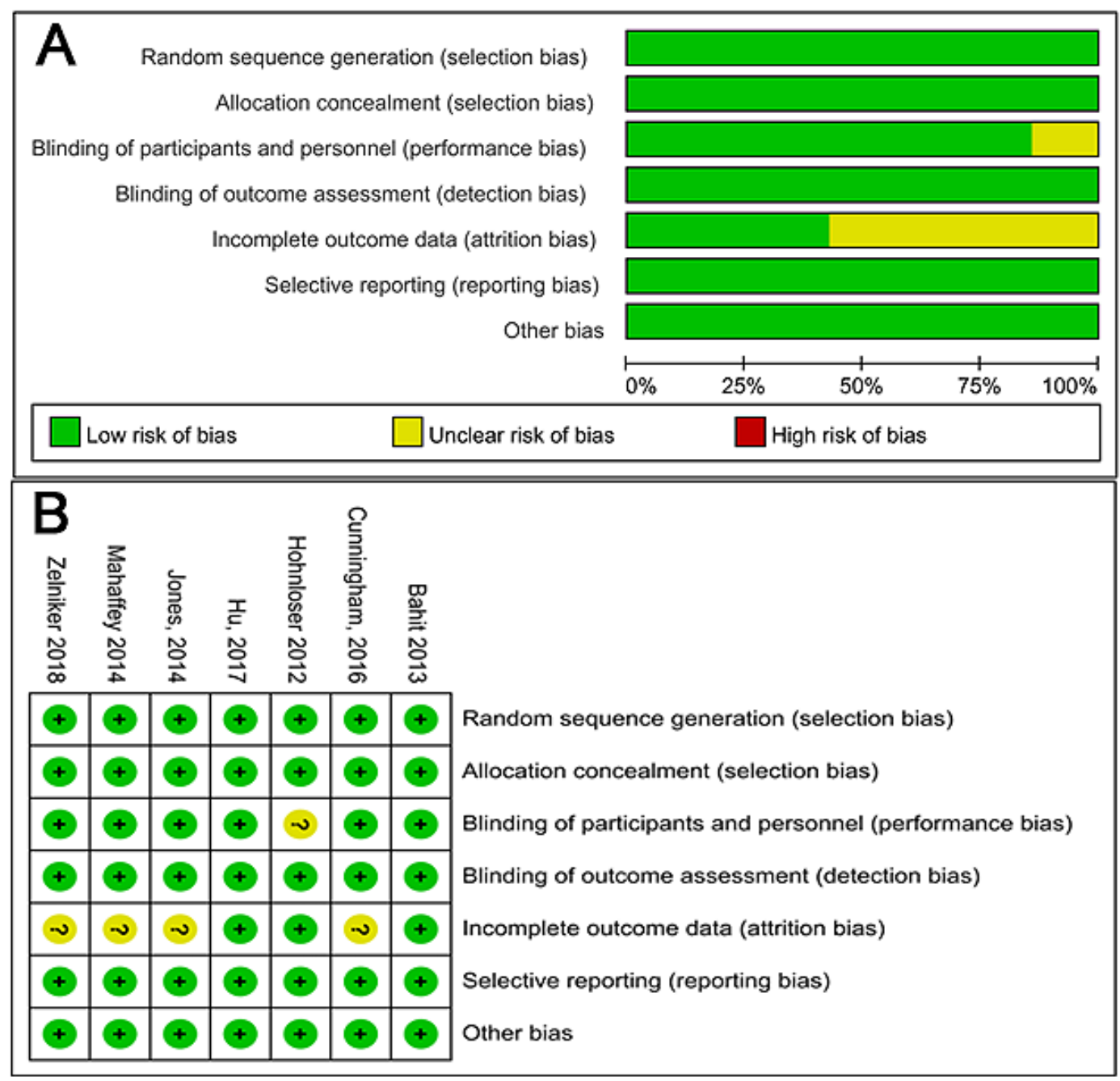

Figure 2. Risk of bias assessment according to the Cochrane risk of bias assessment tool.

0.64-1.90; $\left.P=0.74 ; \mathrm{I}^{2}=0 \%\right)$, and stroke/SEE (RR 0.93; $95 \%$ CI $0.61-1.42 ; P=0.73 ; \mathrm{I}^{2}=1 \%$ ).

Safety of NOACs versus warfarin In comparison with warfarin, NOACs had non-significantly different risk for major bleeding (RR 1.12; 95\% CI $0.70-1.81 ; P=0.63 ; \mathrm{I}^{2}=$ $54 \%$; Figure 4) and intracranial hemorrhage (RR 0.54; $95 \%$ CI $0.16-1.85 ; P=0.33 ; I^{2}=23 \%$; Figure 4$)$ in patients with $\mathrm{AF}$ and PAD.

\section{Discussion}

Overall, in patients with $\mathrm{AF}$ and $\mathrm{CAD}$, compared with warfarin, the use of NOACs was associated with significant reductions in SEE and intracranial hemorrhage, but NOACs had non-significantly different rates of allcause death, cardiovascular death, MI, and stroke. In AF patients with concomitant PAD, NOACs have similar efficacy and safety relative to warfarin. The large sample size from RCTs, high-quality design of studies, and stable results in the subgroup analysis provided reliable findings.

The overall incidence of $\mathrm{CAD}$ in $\mathrm{AF}$ patients is high at $34 \%$, and the incidence is increased to $41 \%$ in $\mathrm{AF}$ pa- tients $>70$ years old. ${ }^{33)}$ In recent years, an increasing number of patients with concomitant $\mathrm{AF}$ and $\mathrm{CAD}$ have been receiving NOACs as their OAC therapy of choice. ${ }^{34,35)}$ However, the role of NOACs in patients with concomitant $\mathrm{AF}$ and $\mathrm{CAD}$ or PAD is unknown. A previous meta-analysi ${ }^{36)}$ has shown that NOACs significantly reduced intracranial hemorrhage in AF patients. Consistently, our study also shows that NOACs were superior to warfarin in reducing the risks of SEE and intracranial hemorrhage in AF patients with CAD or PAD. Overall, NOACs had as favorable of a risk-benefit profile as warfarin in patients with concomitant AF and CAD.

Whether or not dabigatran increases the incidence of MI is controversial. ${ }^{37-40)}$ In our subgroup analysis, we found that NOACs had no differences in the risk of MI in comparison with warfarin. The overall benefit and risk balance of NOACs appear to be favorable in patients with concomitant $\mathrm{AF}$ and $\mathrm{CAD}$ because of the reduction in SEE, and intracranial hemorrhage.

AF patients with concomitant PAD suffer from a worse prognosis, including increased stroke and thromboembolism. $^{41)}$ Hence, PAD has been incorporated into 


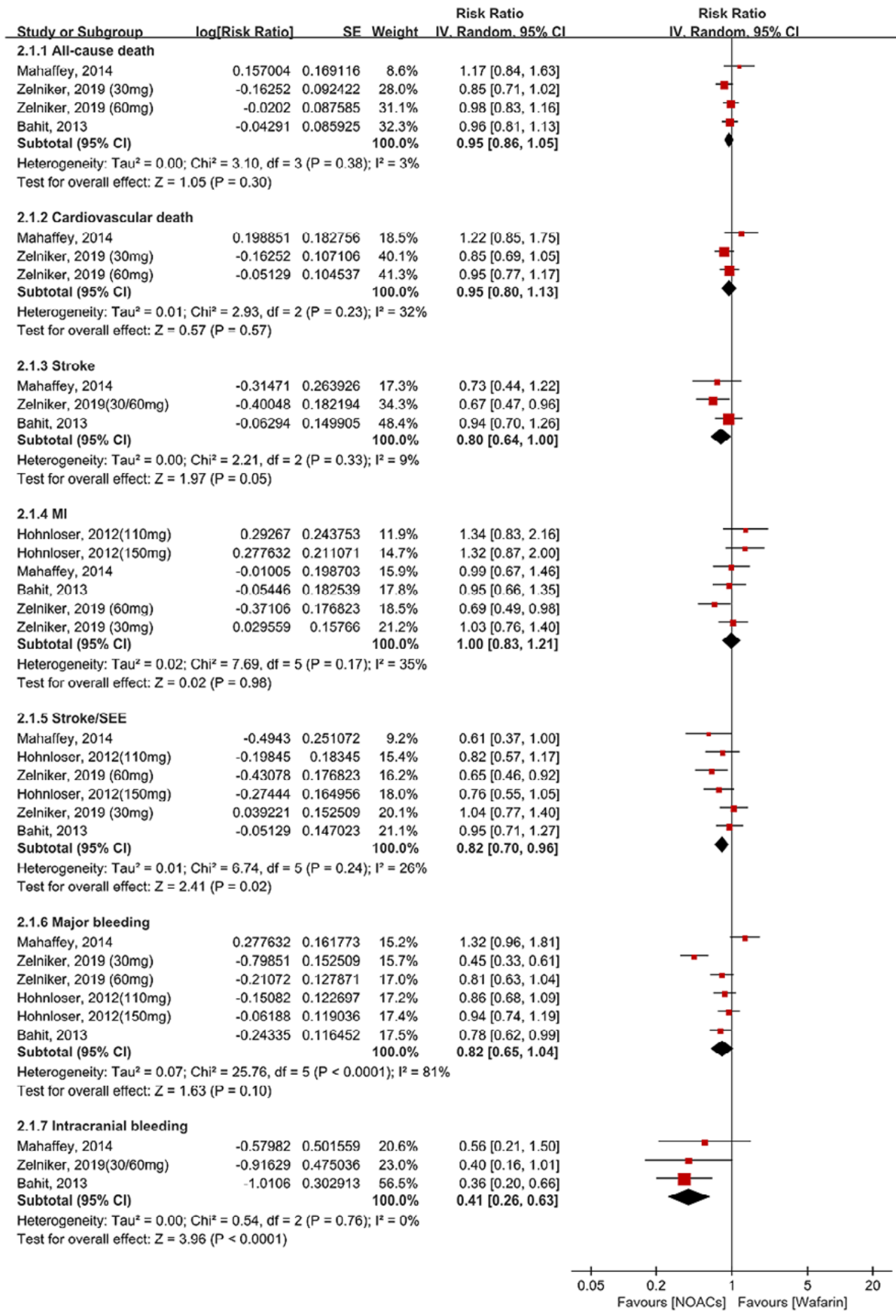

Figure 3. Efficacy and safety of non-vitamin $\mathrm{K}$ versus warfarin in AF patients with $\mathrm{CAD}$. AF indicates atrial fibrillation; CAD, coronary artery disease; MI, myocardial infarction; NOACs, non-vitamin K antagonist oral anticoagulants; and SEE, systemic embolism. 


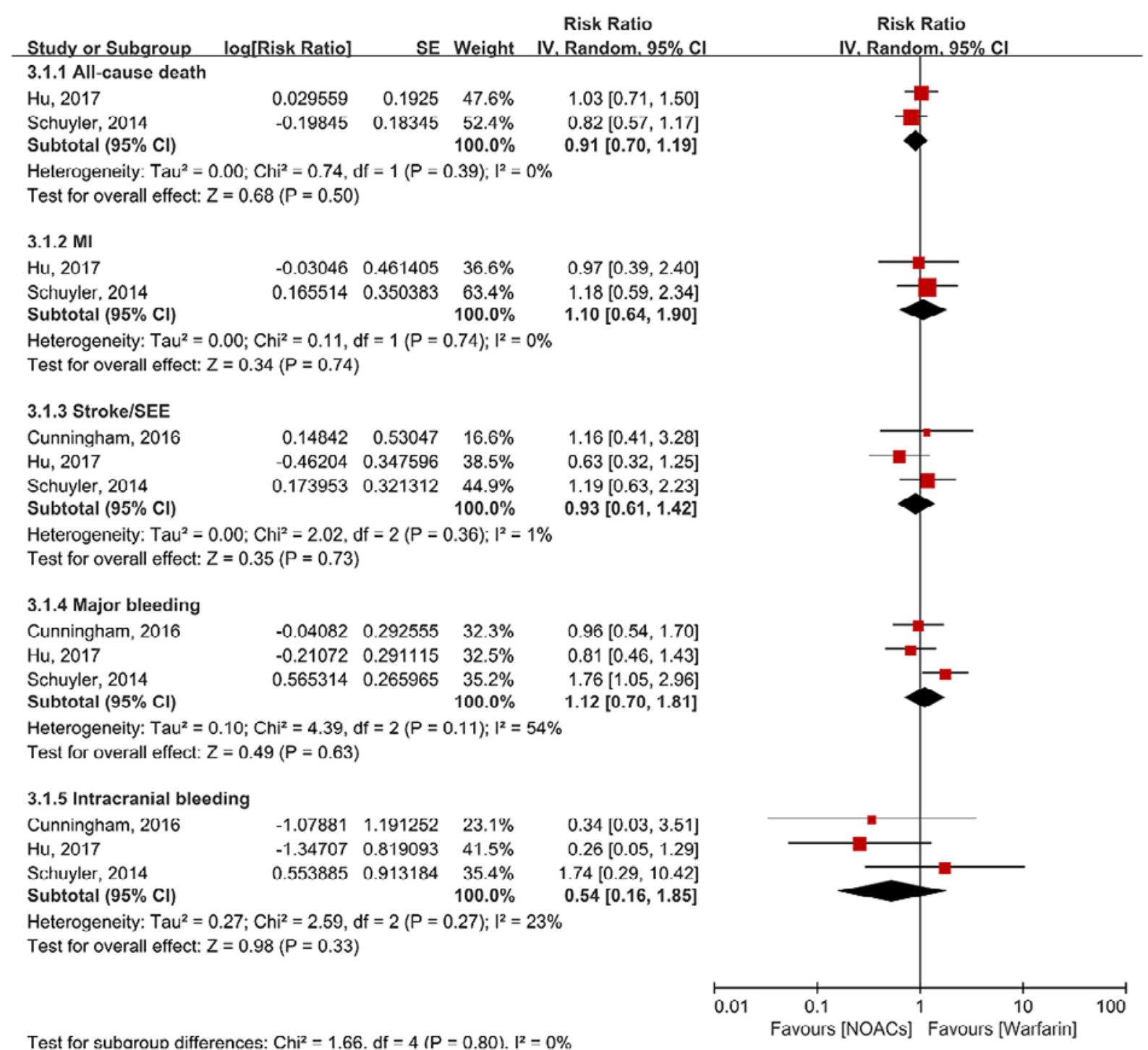

Figure 4. Efficacy and safety of non-vitamin $\mathrm{K}$ versus warfarin in AF patients with PAD. AF indicates atrial fibrillation; MI, myocardial infarction; NOACs, non-vitamin K antagonist oral anticoagulants; PAD, peripheral artery disease; and SEE, systemic embolism.

$\mathrm{CHA}_{2} \mathrm{DS}_{2}$-VASc score to predict the stroke risk in patients with $\mathrm{AF}^{42)}$ However, in $\mathrm{AF}$ patients with oral anticoagulants, there are no differences in the risk of stroke or SEE and major bleeding in patients with PAD and without PAD. ${ }^{18-20)}$ The use of NAOCs is increasing in patients with AF. However, the balance of effectiveness and safety of NOACs in patients with coexisting AF and PAD is still unclear. Our results show that NOACs have similar efficacy and safety relative to warfarin in subjects with AF and PAD.

In patients with $\mathrm{AF}$ and $\mathrm{CAD}, \mathrm{NOACs}$ reduce stroke/ $\mathrm{SSE}$ and intracranial hemorrhage in the CAD group. In patients with $\mathrm{AF}$ and $\mathrm{PAD}, \mathrm{NOACs}$ showed a trend toward lower stroke/SSE rates (RR 0.93; 95\% CI 0.61-1.42; $P=0.73)$ and intracranial hemorrhage rates (RR 0.54; 95\% CI $0.16-1.85 ; P=0.33$ ). The number of patients included may be indicative of differences in outcomes between $\mathrm{CAD}$ and PAD groups. The CAD group included
19267 AF patients with CAD, whereas the PAD group included 2564 AF patients with PAD.

Previous meta-analysis ${ }^{43)}$ emphasized on comparing patients with CAD and non-CAD. In our study, we focused on the role of NOACs in AF patients with CAD or PAD. A similar meta-analysis ${ }^{44)}$ has assessed the effect of NOACs plus antiplatelet therapy and compared with warfarin in $\mathrm{AF}$ patients with concomitant antiplatelet drugs. In this study, NOACs reduced the rates of major bleeding, minor bleeding, and any bleeding. It is important to note that only $30 \%-55 \%$ of AF patients had CAD or PAD at presentation in those studies. In addition, the analysis compared the efficacy and safety of NOACs plus aspirin with warfarin plus aspirin in those patients. In comparison, all of the included AF patients were diagnosed with CAD or PAD in our study.

Strengths and limitations: The strengths of this study include the strict inclusion and exclusion criteria, large sam- 
ple size, and high-quality design. Moreover, a subgroup analysis was carried out to investigate the potential sources of heterogeneity and identify the effect of NOACs in different clinical settings. However, several limitations may influence the validity of this meta-analysis. First, the definition of CAD or PAD differed across the RCTs and potentially affected the findings through selection bias. The subgroup of ROCKET-AF trial only enrolled the patients with prior MI. Second, although all of the drugs were categorized as NOACs, the type, dose, and mechanisms of NOACs used differed across the included studies, which may limit the interpretation of our findings. Nevertheless, similar meta-analyses ${ }^{36)}$ of these RCTs have previously been undertaken for studying the effects of NOACs. Finally, given that the studies included are post hoc analyses, our results are hypothesis-generating rather than definitive.

\section{Conclusions}

Compared with warfarin, NOACs have a better efficacy and safety profile, with significant reductions in stroke/SEE and intracranial hemorrhage in AF patients with CAD. In AF patients with PAD, NOACs have similar efficacy and safety compared with warfarin.

\section{Disclosure}

Conflicts of interest: All Authors declare that we have no conflict of interest.

Ethical approval: This article does not contain any studies with human participants or animals performed by any of the authors.

\section{References}

1. Wolf PA, Abbott RD, Kannel WB. Atrial fibrillation as an independent risk factor for stroke: The Framingham study. Stroke 1991; 22: 983-8.

2. Lip GYH. The abc pathway: An integrated approach to improve af management. Nat Rev Cardiol 2017; 14: 627-8.

3. Lip G, Freedman B, De Caterina R, Potpara TS. Stroke prevention in atrial fibrillation: Past, present and future. Comparing the guidelines and practical decision-making. Thromb Haemost 2017; 117: 1230-9.

4. Cheng CM, Lin CH, Chou P, Jong GP. Antithrombotic treatment may reduce mortality among new-onset atrial fibrillation patients with gray-zone risk of stroke. Int Heart J 2019; 60: 303-9.

5. January CT, Wann LS, Calkins H, et al. 2019 AHA/ACC/HRS focused update of the 2014 AHA/ACC/HRS guideline for the management of patients with atrial fibrillation: a report of the American College of Cardiology/American Heart Association Task Force on Clinical Practice Guidelines and the Heart Rhythm Society. J Am Cardiol 2019; 74: 104-32.

6. Connolly SJ, Ezekowitz MD, Yusuf S, et al. Dabigatran versus warfarin in patients with atrial fibrillation. N Engl J Med 2009; 361: 1139-51.

7. Patel MR, Mahaffey KW, Garg J, et al. Rivaroxaban versus warfarin in nonvalvular atrial fibrillation. N Engl J Med 2011; 365 883-91.

8. Granger $\mathrm{CB}$, Alexander JH, McMurray JJ, et al. Apixaban versus warfarin in patients with atrial fibrillation. $\mathrm{N}$ Engl $\mathrm{J}$ Med 2011; 365: 981-92.
9. Giugliano RP, Ruff CT, Braunwald E, et al. Investigators EA-T Edoxaban. Edoxaban versus warfarin in patients with atrial fibrillation. N Engl J Med 2013; 369: 2093-104.

10. Hansen ML, Sørensen R, Clausen MT, et al. Risk of bleeding with single, dual, or triple therapy with warfarin, aspirin, and clopidogrel in patients with atrial fibrillation. Arch Intern Med 2010; 170: 1433-41.

11. Lip GY, Windecker S, Huber K, et al. Management of antithrombotic therapy in atrial fibrillation patients presenting with acute coronary syndrome and/or undergoing percutaneous coronary or valve interventions: A joint consensus document of the European Society of Cardiology working group on thrombosis, European Heart Rhythm Association (EHRA), European association of percutaneous cardiovascular interventions (EAPCI) and European association of acute cardiac care (ACCA) endorsed by the heart Rhythm Society (HRS) and Asia-pacific Heart Rhythm Society (APHRS). Eur Heart J 2014; 35: 315579.

12. Aboyans V, Ricco JB, Bartelink MEL, et al. 2017 ESC Guidelines on the Diagnosis and Treatment of Peripheral Arterial Diseases, in collaboration with the European Society for Vascular Surgery (ESVS) Document covering atherosclerotic disease of extracranial carotid and vertebral, mesenteric, renal, upper and lower extremity arteries Endorsed by: the European Stroke Organization (ESO) The Task Force for the Diagnosis and Treatment of Peripheral Arterial Diseases of the European Society of Cardiology (ESC) and of the European Society for Vascularsurgery (ESVS). Eur Heart J 2018; 39: 763-816.

13. Lamberts M, Gislason GH, Lip GY, et al. Antiplatelet therapy for stable coronary artery disease in atrial fibrillation patients taking an oral anticoagulant: A nationwide cohort study. Circulation 2014; 129: 1577-85.

14. Hohnloser SH, Oldgren J, Yang S, et al. Myocardial ischemic events in patients with atrial fibrillation treated with dabigatran or warfarin in the RE-LY (randomized evaluation of long-term anticoagulation therapy) trial. Circulation 2012; 125: 669-76.

15. Bahit MC, Lopes RD, Wojdyla DM, et al. Apixaban in patients with atrial fibrillation and prior coronary artery disease: Insights from the ARISTOTLE trial. Int J Cardiol 2013; 170: 215-20.

16. Mahaffey KW, Stevens SR, White HD, et al. Ischaemic cardiac outcomes in patients with atrial fibrillation treated with vitamin $\mathrm{K}$ antagonism or factor $\mathrm{Xa}$ inhibition: Results from the ROCKET AF trial. Eur Heart J 2014; 35: 233-41.

17. Zelniker TA, Ruff CT, Wiviott SD, et al. Edoxaban in atrial fibrillation patients with established coronary artery disease: Insights from ENGAGE AF-TIMI 48. Eur Heart J Acute Cardiovasc Care 2019; 8: 176-85.

18. Jones WS, Hellkamp AS, Halperin J, et al. Efficacy and safety of Rivaroxaban compared with warfarin in patients with peripheral artery disease and non-valvular atrial fibrillation: Insights from ROCKET AF. Eur Heart J 2014; 35: 242-9.

19. Cunningham J, Giugliano R, Braunwald E, et al. Edoxaban versus warfarin in 841 patients with atrial fibrillation and peripheral arterial disease: Insights from the ENGAGE AF-TIMI 48 trial. J Am Coll Cardiol 2016; 67: 2262.

20. Hu PT, Lopes RD, Stevens SR, et al. Efficacy and safety of apixaban compared with warfarin in patients with atrial fibrillation and peripheral artery disease: Insights from the ARISTOTLE trial. J Am Heart Assoc 2017; 6: e004699.

21. Liberati A, Altman DG, Tetzlaff J, et al. The prisma statement for reporting systematic reviews and meta-analyses of studies that evaluate healthcare interventions: Explanation and elaboration. BMJ 2009; 339: b2700.

22. Schulman S, Kearon C. Subcommittee on Control of Anticoagulation of the Scientific and Standardization Committee of the International Society on Thrombosis and Haemostasis. Definition of major bleeding in clinical investigations of antihemostatic medicinal products in non-surgical patients. J Thromb Haemost 2005; 3: 692-4.

23. Higgins JP, Altman DG, Gøtzsche PC, et al. The cochrane col- 
laboration's tool for assessing risk of bias in randomised trials. BMJ 2011; 343: d5928.

24. Fox BD, Kahn SR, Langleben D, Eisenberg MJ, Shimony A. Efficacy and safety of novel oral anticoagulants for treatment of acute venous thromboembolism: Direct and adjusted indirect meta-analysis of randomised controlled trials. BMJ 2012; 345: e7498.

25. Tangelder MJ, Frison L, Weaver D, et al. Effect of ximelagatran on ischemic events and death in patients with atrial fibrillation after acute myocardial infarction in the efficacy and safety of the oral direct thrombin inhibitor ximelagatran in patients with recent myocardial damage (ESTEEM) trial. Am Heart J 2008; 155: 382-7.

26. Larsen TB, Rasmussen LH, Gorst-Rasmussen A, et al. Myocardial ischemic events in 'real world' patients with atrial fibrillation treated with dabigatran or warfarin. Am J Med 2014; 127: 329-36.e4.

27. Sherwood MW, Cyr DD, Jones WS, et al. Use of dual antiplatelet therapy and patient outcomes in those undergoing percutaneous coronary intervention: The ROCKET AF trial. JACC Cardiovasc Interv 2016; 9: 1694-702.

28. Kopin D, Jones WS, Sherwood MW, et al. Percutaneous coronary intervention and antiplatelet therapy in patients with atrial fibrillation receiving apixaban or warfarin: Insights from the ARISTOTLE trial. Am Heart J 2018; 197: 133-41.

29. Gaubert M, Resseguier N, Laine M, Bonello L, Camoin-Jau L, Paganelli F. Dabigatran versus vitamin K antagonist: An observational across-cohort comparison in acute coronary syndrome patients with atrial fibrillation. J Thromb Haemost 2018; 16: 465-73.

30. Gibson CM, Mehran R, Bode C, et al. Prevention of bleeding in patients with atrial fibrillation undergoing PCI. N Engl J Med 2016; 375: 2423-34.

31. Cannon CP, Bhatt DL, Oldgren J, et al. Dual antithrombotic therapy with dabigatran after PCI in atrial fibrillation. N Engl J Med 2017; 377: 1513-24.

32. Gibson CM, Pinto DS, Chi G, et al. Recurrent hospitalization among patients with atrial fibrillation undergoing intracoronary stenting treated with 2 treatment strategies of Rivaroxaban or a dose-adjusted oral vitamin $\mathrm{K}$ antagonist treatment strategy. Circulation 2017; 135: 323-33.

33. Kralev S, Schneider K, Lang S, Süselbeck T, Borggrefe M. Incidence and severity of coronary artery disease in patients with atrial fibrillation undergoing first-time coronary angiography.
PloS one 2011; 6: e24964.

34. Sindet-Pedersen C, Staerk L, Lamberts M, et al. Use of oral anticoagulants in combination with antiplatelet(s) in atrial fibrillation. Heart 2018; 104: 912-20.

35. Gao X, Ge Z, Kong X, et al. Clinical outcomes of antithrombotic strategies for patients with atrial fibrillation after percutaneous coronary intervention. Int Heart J 2019; 60: 546-53.

36. Ruff CT, Giugliano RP, Braunwald E, et al. Comparison of the efficacy and safety of new oral anticoagulants with warfarin in patients with atrial fibrillation: A meta-analysis of randomised trials. Lancet 2014; 383: 955-62.

37. Uchino K, Hernandez AV. Dabigatran association with higher risk of acute coronary events: Meta-analysis of noninferiority randomized controlled trials. Arch Intern Med 2012; 172: $397-$ 402.

38. Carmo J, Moscoso Costa F, Ferreira J, Mendes M. Dabigatran in real-world atrial fibrillation. Meta-analysis of observational comparison studies with vitamin $\mathrm{K}$ antagonists. Thromb Haemost 2016; 116: 754-63.

39. Douxfils J, Buckinx F, Mullier F, et al. Dabigatran etexilate and risk of myocardial infarction, other cardiovascular events, major bleeding, and all-cause mortality: A systematic review and meta-analysis of randomized controlled trials. J Am Heart Assoc 2014; 3: e000515.

40. Artang R, Rome E, Nielsen JD, Vidaillet HJ. Meta-analysis of randomized controlled trials on risk of myocardial infarction from the use of oral direct thrombin inhibitors. Am J Cardiol 2013; 112: 1973-9.

41. Olesen JB, Lip GY, Lane DA, et al. Vascular disease and stroke risk in atrial fibrillation: A nationwide cohort study. Am J Med 2012; 125: 826.e13-23.

42. Kirchhof P, Benussi S, Kotecha D, et al. 2016 ESC Guidelines for the management of atrial fibrillation developed in collaboration with EACTS. Eur Heart J 2016; 37: 2893-962.

43. Zelniker TA, Ruff CT, Antman EM, Giugliano RP. The efficacy and safety of non-vitamin $\mathrm{k}$ antagonist oral anticoagulants in patients with atrial fibrillation and coronary artery disease: A meta-analysis of randomized trials. Eur Heart J Acute Cardiovasc Care 2018; 2048872618796990.

44. Bennaghmouch N, de Veer AJWM, Bode K, et al. Efficacy and safety of the use of non-vitamin $\mathrm{k}$ antagonist oral anticoagulants in patients with nonvalvular atrial fibrillation and concomitant aspirin therapy: A meta-analysis of randomized trials. Circulation 2018; 137: 1117-29. 